\title{
The Using of Controlled Cavitation Processes in Some Engineering and Agricultural Applications
}

\author{
Kanat M Dyussenov ${ }^{1, *}$, Janna Dyussenova ${ }^{2}$, Ivan Nedugov ${ }^{2}$ \\ ${ }^{1}$ The Innovative Eurasian University, 140000, Pavlodar, Kazakhstan \\ ${ }^{2}$ InnoMix Ltd, 140000, Pavlodar, Kazakhstan \\ *Corresponding Author: kdyussenov@yandex.ru
}

Copyright (C) 2013 Horizon Research Publishing All rights reserved.

\begin{abstract}
On the basis of information on impact of ultrasonic and hydrodynamic cavitation on water in various engineering and agrochemical applications parameters of the frequencies favoring to an intensification of growth of some grades of tomatoes, shanks of decorative roses and saplings of a pine ordinary are defined. The example of the engineering application of operated hydrodynamic cavitation on the basis of the independent generator of warmth for heating is presented. This example was patented and successfully used further for water structuring in some agrochemical applications. Results of researches of influence of acoustic radiations in the range of frequencies of $20 \mathrm{~Hz}-$ $50 \mathrm{kHz}$ and operated hydrodynamic cavitation on growth of some types of plants and data on influence of the specified private range on some physical and chemical properties of irrigation water are presented. It is shown that for a productive drop irrigation of skilled plants the range of ultrasonic radiation in a range close to $20 \mathrm{kHz}$ which leads to increase of concentration of microcells of the metals dissolved in irrigation water is most effective and also influences favorable change of $\mathrm{pH}$ of irrigation water. Experimentally an established fact of increase of productivity of tomatoes for $15 \%$ at rather short-term period of watering by the structured water and considerable effect of increase in growth of root system at saplings of decorative roses. Also established an experimentally fact of decrease in an electric conductivity of irrigation water after hydrodynamic cavitational impact on $18-23 \%$, along with favorable change of $\mathrm{pH}$ of water. Some factors influencing an intensification of growth of saplings and development of root system with considerable decrease in pathogenic micro flora are analyzed and revealed.
\end{abstract}

Keywords Ultrasound, Acoustic Radiations, Cavitation, Masses Spectrometer Analysis, Infrasound, Piezoelectric Radiators, Frequency Range

\section{Introduction}

A range of technical applications of hydrodynamic and ultrasonic cavitation rapidly increases in the world being directly used in medicine, naval applications, pharmaceutics, chemical technologies, cosmetics and cosmetology, etc. In our case we consider a method of generation of controlled hydrodynamic and ultrasound (acoustic) cavitation. It is necessary to note, that the thermodynamic effect of cavitation experimentally received on the trial installation obviously confirms the fact of presence and accompanying complex cavitation effects there are characteristic for ultrasound cavitation.

The analysis literary given both scientific and taken from the Internet allows making practically unequivocal conclusion that the thermodynamic effect of hydrodynamic cavitation is the integral part of the interconnected and complex effects of cavitation. These are such effects as sono-luminescence, having dug intermolecular connections in the cavitation's cavities, water ionization, highly effective emulsification and homogeneous phenomenon, de-aeration and change of the structural characteristics of the water, etc.

Use of hydrodynamic cavitation as a heat-carrier for water heating is well known. The unconditional leader in world technology of the given method is the US Company Hydro Dynamics, Inc. [1]. Researches of the Ukrainian companies IterEnergoResurs Ltd. and TEKMASH [2] are of interest also.

The application of ultrasonic cavitation in medicine and biomedicine also has a rather wide range in embryology and experimental morphology [3], therapeutics practice [4], of microbiology and biochemistry $[5,6]$.

The American company Flowserve is known also, developing the equipment for management and prevention of hydrodynamic cavitation in the various industrial applications.

The production of the American company Arisdyne Systems, Inc. is of interest on application of controlled hydrodynamic cavitation for preparation of highly effective mixes of a biodiesel and ethanol. The reduction of a level of nitrogen oxides, carbon dioxides and liquid fuel flow is represented also by the American company Cavitation Technologies, Inc. [7], confirming that controlled 
hydrodynamic cavitation is one of the shown aspects of nano-technology. The disinfectant and bacteriological effects of hydrodynamic cavitation is confirmed by experiments as for example [8].

Are perspectives also development of numerical methods of hydrodynamic cavitation research of the American and Japanese scientists in the field of increasing of diesel engines efficiency [9]. The researches in the field of hydrodynamic effects of cavitation are actively being made by Japanese scientists [10] in the field of possible applications for various materials processing.

The data brief analysis taken from the Internet, despite of their fragmentariness shows that a range of controlled cavitation usage promptly extends. The submitted review of practical and scientific data from major industrial countries in the field of practical and commercial use of controlled cavitation allows making a conclusion about an obvious topicality and future trends of development of this direction.

Shown disinfectant and bacteriological effects after influence on water of hydrodynamic cavitation can be used in water supply systems, manufacture of bottled water with the structured water for medical purposes, for cooling drinks and tonics.

There are proven in practice, data on the nanostructuring of water after cavitation effects and it is used in agriculture to increase yields of different crops after irrigation of treated water. A number of the made experiments on an example of an intensification of growth of tomatoes at influence ultrasonic cavitation, and also influences nanostructuring waters after hydrodynamic cavitation on growth of saplings of coniferous breeds will be resulted in given article. The proposed scientific and technical results could easily be implemented for these purposes, and various aspects of biotechnology.

Published a series of papers on the positive effects of hydrodynamic cavitation in various processes in chemical industry, biochemistry. The proposed results can also be used to create a system of directed transportation of biologically active substances into cells, in particular for increasing the therapeutic activity of drugs and cosmetics. Preparations created on the basis of structuring water and other solutions effect will be needed in biology, pharmacology, cosmetics, veterinary and food industries.

\section{Materials and Methods}

\subsection{The Using of Thermodynamic Effect of Hydrodynamic Cavitation}

Use of hydrodynamic cavitation as a heat-carrier for water heating is wide known and also are presented earlier $[1,2]$. For the practical realization of artificially created and controlled hydrodynamic cavitation the author designed [11] and patented [CAVITATION HEAT GENERATOR, PPA USA 61/745,770 from 25.12.12] knot - the cavitational generator of warmth. As basic element of this nozzle Venture's specially designed pipe schematically shown on the Figure 1, where shows a fragment of a series of calculations on the 3-D model [12] which were carried out in parallel with experimental research was conducted illustrative confirming the nature of the flow. As can be seen from Figure 1 twisting blades embedded and provide in areas of transition of a confuser part in diffuser and such a construction permits separation of a boundary layer of water from the wall zone and the focus of the collapse of bubbles in the centre of the beginning of diffuser part of the Venture's nozzle.

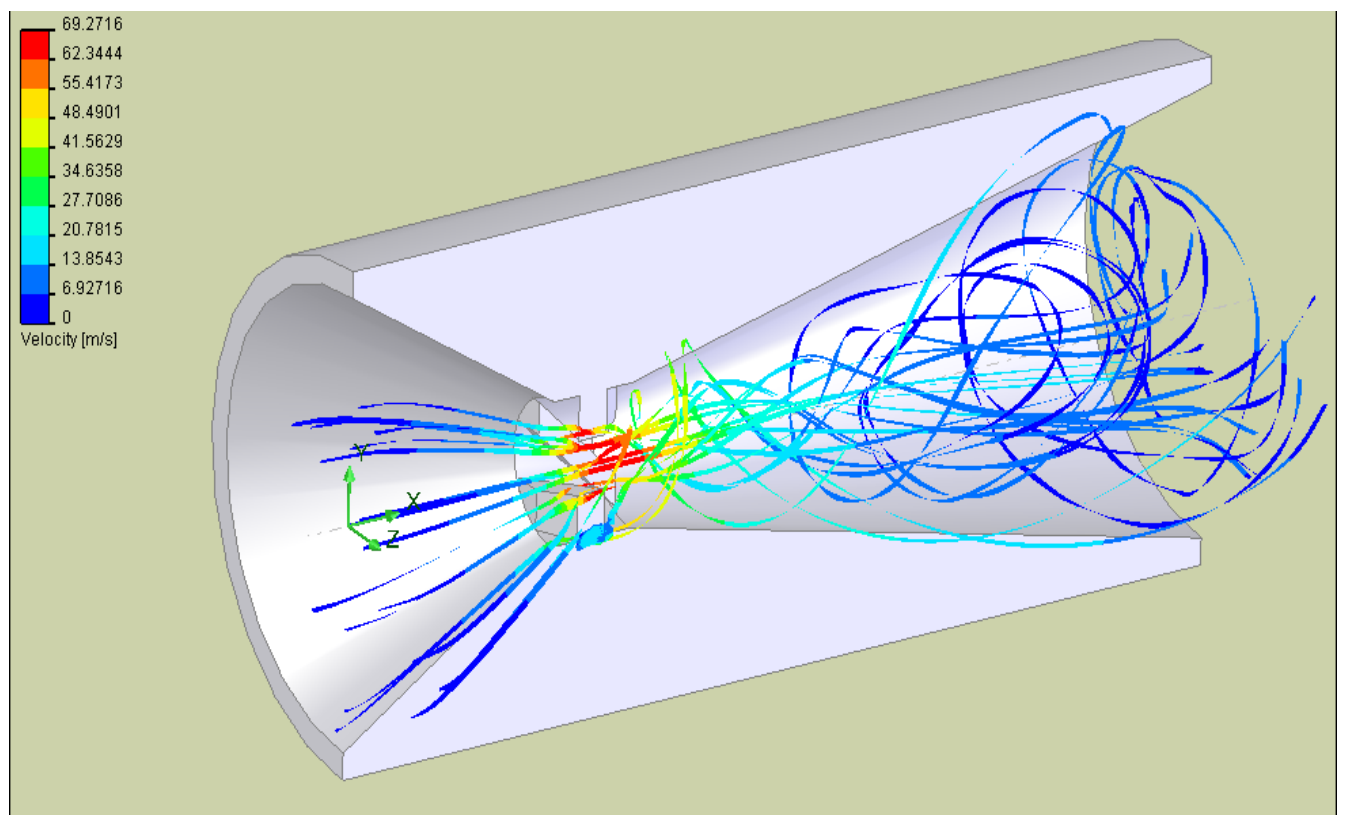

Figure 1. The schemes of the nozzle of Venture's and fragment of 3-D model calculation 
The developed method of heat generation (figure 2) competes with traditional heating plants with fuel or electric heating of the heat carrier in which the efficiency is $98 \%$. In this case it is not required special systems of water preparation and use of fuel, and the absence of electric heating makes installation more secure in operation.

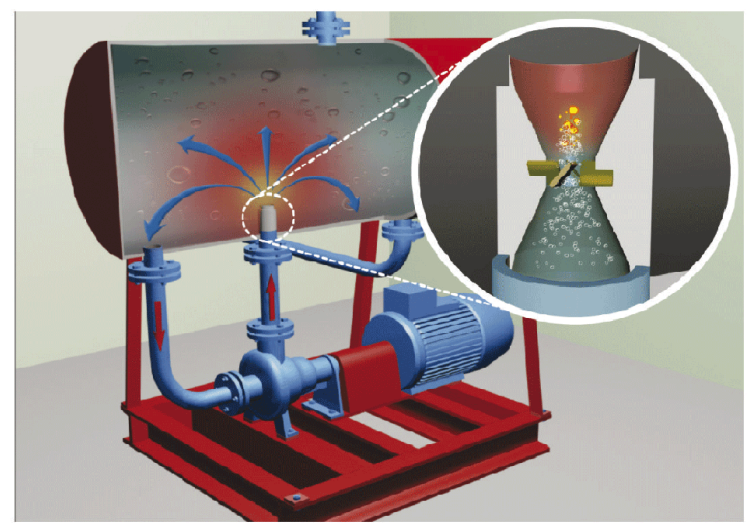

Figure 2. The scheme of operation of heat generation unit

Created on the basis of the obtained effect industrial prototype heat generator (figure 3 ) has passed successful tests. The reliability of the device is equivalent to the reliability of the motor and pump, a resource whose overhaul is currently 20 - 30 years.

Relying on long-term experience of application of fertilizers and top dressing by cultivation of a pine ordinary in forestry enterprises, we in addition applied the new system of watering based on a method of impact on water of operated hydrodynamic cavitation. The cavitational nozzle Venture's was involved on the skilled and experimental line of watering of annual segment of a pine.

Except fixing of growth of temperature of irrigation water on the average on $2,8^{0} \mathrm{C}$, at pressure in the pipeline 2,2 of bar water selections were made for measurement of its electric conductivity and $\mathrm{pH}$ also.

Watering by the processed water after influence hydrodynamic cavitation has increased growth of root system of saplings of a pine ordinary and has raised their resistibility to pathogenic micro flora. The experimental fact of decrease in an electric conductivity for $18-23 \%$ with reduction of values $\mathrm{pH}$ for $25-35 \%$ with the corresponding decrease in acidity of irrigation water was noticed. Measurements of tests of water were made for comparison of reliability of the received data on the basis of Innovative Euroasian University (Pavlodar, Kazakhstan) and the Central factory laboratory of the large metallurgical complex KSP Steel Ltd. (Pavlodar, Kazakhstan). The fact of favorable impact on an intensification of growth of plants is known at decrease in an electric conductivity (and content of salts) of water.

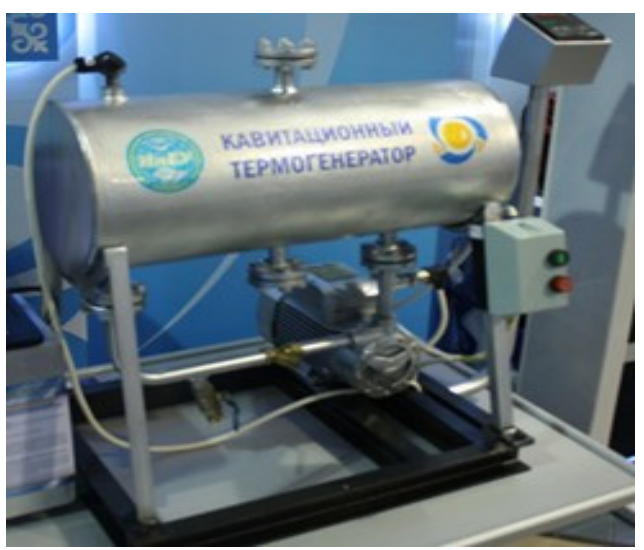

Figure 3. The industrial prototype of cavitation heat generator

The length of roots of sprouts in experience has increased by $5-12 \mathrm{~mm}$ in comparison with control; the root system is more developed (Table 1).

\subsection{The Structuring of Water by the Ultrasound Cavitation}

Two experimental installations for generation of infrasonic and ultrasonic fluctuations with the subsequent transfer of an impulse on piezoelectric converters (radiators) were created.

The block of generation consists of the generator of impulses of a special form and frequency, the block of a signal strengthening capacity and the control panel [CAVITATION ENERGY CONVERTER, PPA USA 61/745,772 from 25.12.12]. Direct impact on water is carried out in the radiation block via piezoelectric converters (Figure 4).The frequency range of radiations before experiments on watering with impact of acoustic fluctuations was fixed by means of a broadband oscillograph of the VALLEMAN PC SGU250 brand and made an adjustable range from $20-50 \mathrm{~Hz}$ on the first device and $20-50 \mathrm{kHz}$ on the second.

Table 1. Illustration of the influence of cavitation on the growth of ordinary pine seedlings

\begin{tabular}{|c|c|c|c|c|c|}
\hline \multicolumn{5}{|c|}{ Length of roots, $\mathrm{mm}$} \\
\hline \multicolumn{2}{|c|}{ Seeds of the first order } & \multicolumn{2}{|c|}{ Seeds of the second order } & \multicolumn{2}{|c|}{ Seeds of the third order } \\
\hline control & experiment & control & experiment & control & experiment \\
\hline 108 & 112 & 520 & 532 & 256 & 260 \\
\hline
\end{tabular}




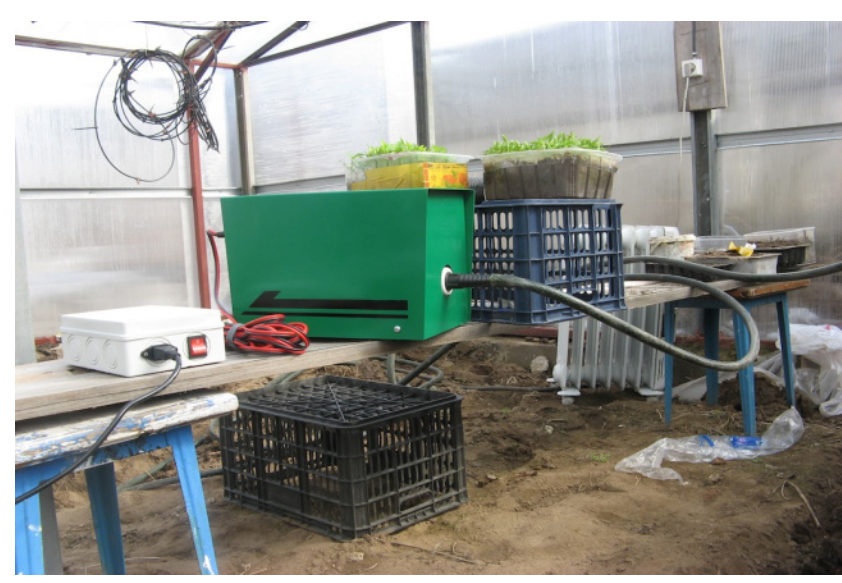

Figure 4. The device for generation of infrasonic and ultrasonic fluctuations

Experiences were made since the beginning of spring on the end of October of the 2012, on the basis of an experimental hothouse with a polycarbonate covering for cultivation of tomatoes (Lycopersicon esculentum Mill) in the size of $6 * 3 * 12 \mathrm{~m}$, located in the suburb Pavlodar (Republic of Kazakhstan: North region). Water moved on system of a drop irrigation of the GARDENA Company (Germany), through one branch of a hose the drop irrigation of 100 plants by simple water from the local well, the second the same water, after passing through intermediate capacity with piezoelectric radiators was carried out. The capacity design with two piezoelectric radiators shipped in it processed by pressurizing structure, for a corrosion exception, represented the channel of specially developed form for the organization of a turbulization of a current with receiving effect of the best mixture of water flow.

During experiments with periodicity of times in 5-6 days water tests for measurement of $\mathrm{pH}$ and the mass and spectrometer analysis were selected. $\mathrm{pH}$ - a metrical was made on laboratory base of Eurasian Innovative University with duplication of measurements $\mathrm{pH}$ on the basis of the Central factory laboratory JSC Aluminums of Kazakhstan combined with the mass and spectrometer analysis on.

equipment of the MALVERN company (Great Britain), allowing to measure 28 chemical elements. Laboratory equipment has the Kazakhstan and international metrological certificate. The way of generation controlled acoustic (ultrasonic) cavitation for processing of irrigation water in a hothouse for cultivation of tomatoes and shanks of decorative

Roses is fully realized and approved. As a result of researches the following facts were established.

Results have surpassed all expectations, for example productivity of tomatoes, has increased on $15 \%$ of all for 5-7 watering, the root system of decorative roses has increased by $40 \%$. Having watered the processed $20 \mathrm{~Hz}$ led to the strongest oppression of plants, after 6-7 watering to a disease of plants Tmv (a virus of a tobacco mosaic), however after change of frequency of acoustic fluctuations on $50 \mathrm{~Hz}$ growth and development of plants were restored after 5 watering. The highest efficiency gave having watered, subjected to influence by ultrasound in a range close to 20 $\mathrm{kHz}$ on the second experimental device.

Results the presented spectrograms in $\mathrm{mg} / \mathrm{dm} 3$ (Figure 5-8) showed that strongly pronounced positive influence on growth of tomatoes at a frequency range of radiation of 20 $\mathrm{kHz}$ rendered growth of concentration of the content of copper by $52 \%$, gland for $22 \%$, zinc almost in 70 times, tin in 8 times, cadmium in 3.9 times. Thus insignificant, on the average on $1.14-2.01 \%$ acidity $(\mathrm{pH})$ of the irrigation processed water grew at $20 \mathrm{kHz}$, and at frequency $50 \mathrm{kHz} \mathrm{pH}$ values increase for $3,28 \%$. The analysis of the provided spectrograms and measurement of $\mathrm{pH}$ of irrigation water after ultrasound influence allowed drawing a conclusion that water gains the new properties connected with its partial ionization, its molecular structure bringing to change.

On collecting fruits tomatoes (Lycopersicon esculentum Mill) processed by the structured water, advanced tomato bushes which poured down simple water in growth rates. From skilled plants $285 \mathrm{~kg}$ of tomatoes and from control only $243 \mathrm{~kg}$ (growth on 15\%) were received for the entire period of experimental watering.

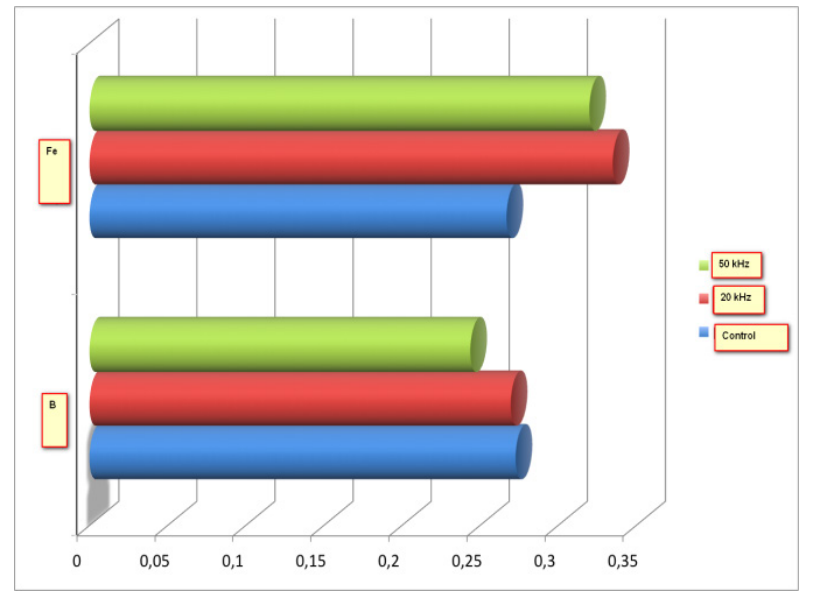

Figure.5. The behavior of concentration of ferric $(\mathrm{Fe})$ in the structuring water

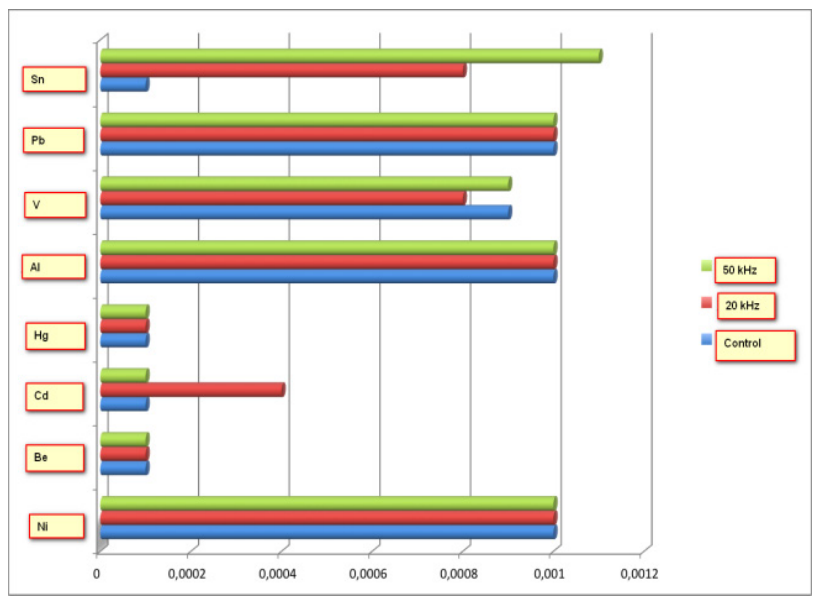

Figure. 6. The behavior of concentration of selenium ( $\mathrm{Sn}$ ) and cadmium (Cd) 


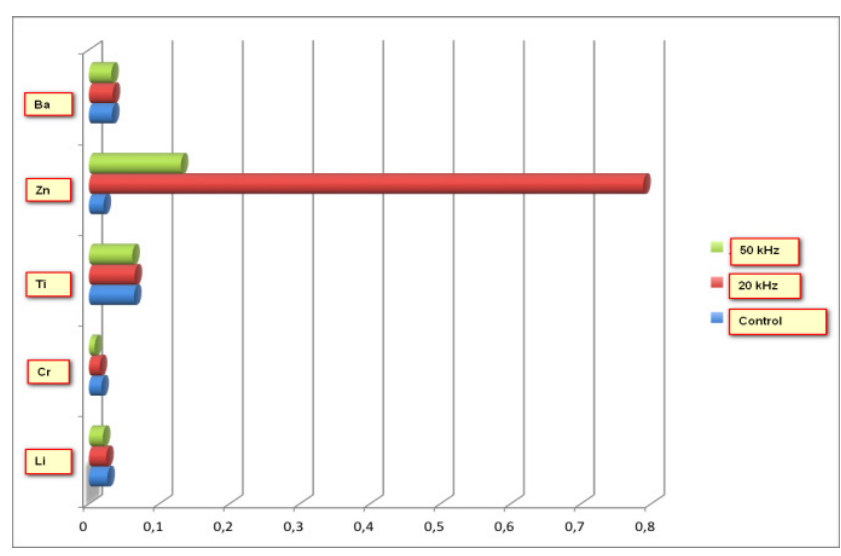

Figure. 7. The growth of the concentration of zinc ( $\mathrm{Zn})$

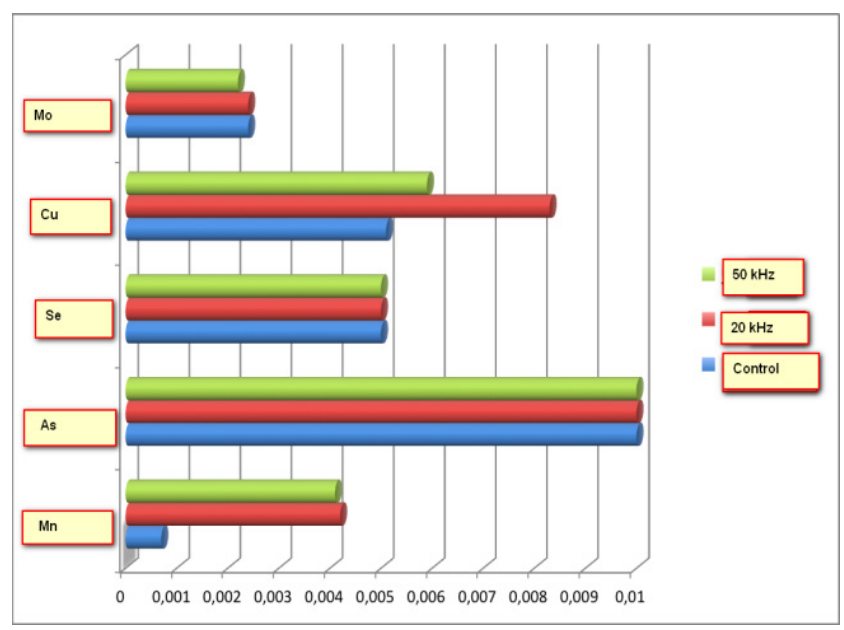

Figure 8. The growth of the concentration of cuprum $(\mathrm{Cu})$

Thus 6-7 watering of $20 \mathrm{kHz}$ made at frequency allowed to increase productivity for $15 \%$. The plants watered structured in October had new brushes, blossomed, i.e. did not feel approach of autumn, and at control plants leaves turned yellow, their most part was lost.

It is possible to draw with high degree of reliability a conclusion that using various ranges of radiation of ultrasound it is possible to influence physical and chemical properties of water to some extent. It is confirmed also by the made experiments. Against primary results on ranges of the acoustic fluctuations made on irrigation water of $20 \mathrm{kHz}$ (the increase in the general productivity at $15 \%$ after 7-8 drop watering, about 13-18 days) is quite probable to predict an intensification of growth of land vegetable cultures and obviously growth of their productivity (the fixed increase in the size of fruits at 50-95\%). Figure 9 showed a fragment of results of experiences.

Apparently that a number of tomatoes (Lycopersicon esculentum Mill) at the left, watered by usual water already stopped the existence, and the right row, when watering by the water processed by ultrasound continues the rapid growth and fructification.

There are proven in practice, data on the nanostructuring of water after cavitation effects $[13,14]$ and it is used in agriculture to increase yields of different crops after irrigation of treated water. Structured water has a positive impact on development and productivity in the livestock area (poultry, pigs, cattle production and animal health). The proposed project could easily be implemented for these purposes, and various aspects of biotechnology.

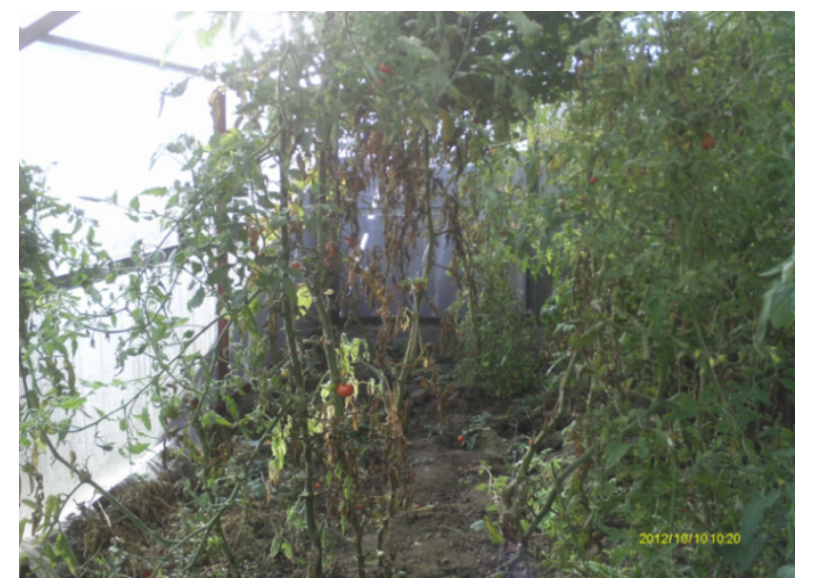

Figure 9. The illustration of the effectiveness of influences of ultrasound cavitation to tomatoes

Biotechnological aspects also associated with the nanostructure of water certainly can attract pharmaceutical and cosmetic companies and concerns. Implemented technology (structural dispersion) transportation of various lipids, hydrophilic enzyme and other various components in the molecular structure of water or other liquid environments will create new classes of highly effective drugs and cosmetics [15]. Also known technology of obtaining the microchelate fertilizers on the basis of cavitation [16]

\section{Conclusion}

Actuality and relevance of practical applications is beyond doubt. The boom in demand for nanotechnology, new technologies in different ways to structure the water, other liquids and solutions increases with geometric progression. The proposed method of cavitation effects on water is easy, relatively cheap, low weight and size, reliability, durability, low power consumption (electric power necessary pumps does not exceed 1,5-2,2 $\mathrm{kW}$ in the case of hydrodynamic cavitation), environmental cleanliness and combining the complex effects of controlled cavitation.

Phase of scientific and technical studies and research (R\&D) is almost done in the context of production and the generation of controlled cavitation effect and the establishment of experimental - industrial plants for the production of heat and irrigation water, as a concomitant effect and increase of productivity of tomatoes and shanks of decorative roses.

Data are derived by studying the materials of the International Committee on Water Resources at the UN and the WHO shoes that the main problem of the humanity after 2025 will be the water problem and water by this time 
becomes strategic recourse.

If to take as a basis some directions on which any company is focused, as following: Water sanitation, Forestry and Agriculture, Foods industry, Water-sustainable use, Chemical, Biotechnologies, it is possible to say, and that the offered investigations for technical collaboration will be coordinated to many fields of the Inventions in modern and perspective activity and directions.

\section{REFERENCES}

[1] The Shock Wave Power Reactor, Online available from http://hydrodynamics.com

[2] Hydrodynamic Technologies, Online available from http://www.tekmash.ua

[3] Chuang YH, Cheng PW, Chen SC, Ruan JL, Li PC. Effects of ultrasound-induced inertial cavitation on enzymatic thrombolysis, Department of Electrical Engineering, National Taiwan University, Taipei, Taiwan. Ultrason Imaging. Apr. 32(2), 81-90, 2010.

[4] P. Riesz, D. Berdahl, and C. L. Christman. Free radical generation by ultrasound in aqueous and nonaqueous solutions, Environ Health Perspective, December: 64, 233-252, 1985.

[5] D. Hernández-García, S. Castro-Obregón, S. Gómez-López, C. Valencia, L. Covarrubias. Cell death activation during cavitation of embryoid bodies is mediated by hydrogen peroxide, Experimental Cell Research, Vol. 314, Issue 10, June, 2090-2099, 2008.

[6] A.A. Al-Mahrouki, R. Karshafian, A. Giles, G.J. Czarnota. Bioeffects of ultrasound-stimulated microbubbles on endothelial cells: Gene expression changes associated with radiation enhancement in vitro, Ultrasound Med Biol. Vol. 38, 1958-1969, 2012.
[7] Green Nanotechnology and Environmental Protection, Online available from http://www.ctinanotech.com

[8] G. Loraine , G. Chahine , C.T. Hsiao ,J.K. Choi ,P. Aley. Disinfection of gram-negative and gram-positive bacteria using DynaJets ${ }^{\circledR}$ hydrodynamic cavitating jets, Ultrason Sonochemistry, Vol. 19(3), 710-715, 2012.

[9] Trinh Ngoc Tuan, Hiroshi Okada, Tatsuro Tsukamoto, Kenji Ohe and Katsuzo Iwasawa. Effect of Rounding-off Nozzle Hole Inlet on Fuel Injection and Combustion Characteristics under High-Temperature and High-Pressure, JIME, Vol.42, No.2, 231-239, 2007

[10] Kuwabara Mamoru, Yo Ken, Kubo Takashi. Sono-processin $\mathrm{g}$ of materials based on an acoustic cavitation phenomenon, Journal of Current Advances in Materials and Processes, 962-969, Vol.18, N.4, 2005.

[11] K.M. Dyussenov, E.D. Sergievsky. Generation effect of the heating a liquid by means of controlled cavitation, 6th International Conference on Boiling Heat Transfer, Spoleto, Italy, 135-139, 2006.

[12] A. Adomavichus, K. Dyussenov, V. Grigas. Experimental investigation of thermal cavitation's effect, Scientific Conference by Investigation and Development of Power Energy, Kaunas, Lithuania, 47-52, 2006.

[13] G.F. Byrne, J.E. Begg*, G.K. Hansen. Cavitation and resistance to water flow in plant roots, Journal of Agricultural Meteorology, Vol.18, Issue 1, 21-25.

[14] V. A. Kulagin, T. A. Kulagina. Nanotechnology Cavitational Effects in the Heat-and-Power, Journal of Siberian Federal University, Engineering \& Technologies 1, 2008, 76-85.

[15] C. Coussios, R. Roy. Applications of Acoustics and Cavitation to Noninvasive Therapy and Drug Delivery. Annual Review of Fluid Mechanics. Vol. 40, 395-420.

[16] Nanotechnology and Micro fertilizers, Online available from www.nanomix.biz 